\title{
A contextualização no ensino de equações - uma análise em um livro didático antes e depois do PNLD
}

\author{
The contextualisation in equation education - an analysis in a textbook \\ before and after PNLD
}
Edelweis Jose Tavares Barbosa edelweisb@yahoo.com.br

Anderson Albuquerque Mendes anderson_eu@hotmail.com

\begin{abstract}
Resumo
Esse artigo analisou as formas de contextualização que tem sido utilizadas para o ensino de equações nos livros didáticos, observando quais as mudanças que ocorreram passados 12 anos desde a implantação do Programa Nacional do Livro Didático. Para isso buscamos observar quais livros didáticos estiveram presentes desde a primeira versão do PNLD até os dias atuais, em seguida buscamos realizar a categorização das formas de contextualização nos capítulos destinados ao ensino de equações do primeiro grau com uma variável, categorias estas que foram estruturadas a partir do trabalho de Silva e Santos (2004) a respeito de contextualização. E por fim realizamos a comparação entre os resultados obtidos nos livros antes e depois da implantação do PNLD. Em nossos resultados finais podemos constatar que as principais formas de contextualização utilizadas antes do PNLD mantiveram-se como as mais utilizadas, no entanto apresenta-se agora de maneira mais harmonizadas, sendo estas a contextualização em praticas sociais e em contextos internos a matemática.
\end{abstract}

Palavras-chave: Contextualização; Equações; Livro Didático.

\begin{abstract}
This article analyzed the forms of contextualization that has been used for teaching equations in textbooks, noting what changes occurred the past 12 years since the implementation of the National Textbook Program. For this we seek to see which textbooks were present from the first version of PNLD to the present day, then we seek to perform the categorization of forms of contextualization in chapters dedicated to the education of first degree equations with variable categories these were structured from Silva and Santos work (2004) on contextualization. Finally we perform the comparison between the results obtained in the books before and after the implementation of PNLD. In our final results we can see that the main forms of contextualization used before PNLD remained as the most used, however it has now more harmonized way, which are the context in social practices and internal contexts mathematics.
\end{abstract}

Keywords: Contextualization; equations ; Textbook.

\section{Introdução}

Não é de hoje que o ensino de matemática vem passando por problemas em todos os seus níveis de ensino, problemas esses que muitas vezes são refletidos na baixa compreensão dos alunos e também em suas notas. Um dos problemas que ocorre frequentemente é que o conteúdo é apresentado de maneira estática e desligado de qualquer sentido pratico para o aluno, o que é contrario ao que segundo Santos (2007) realmente deveria acontecer, para ele “A matemática não é uma ciência cristalizada e imóvel; ela está afetada por uma contínua 
expansão e revisão dos seus próprios conceitos." Dessa forma cabe ao professor fazer a mediação entre conteúdo aluno, de forma que os discentes consigam fazer ligações do conteúdo que estão aprendendo com aquilo que já aprenderam, além daquilo que vivem em seu cotidiano, ou ainda com aquilo que estudam em outras disciplinas, ou seja, cabe ao professor trazer o conteúdo de maneira contextualizada, acreditamos assim que o ensino de matemática abordado desta forma pode vir a ser melhor compreendido pelos alunos.

Apropriando-nos de tal concepção propomos como tema deste trabalho investigar as formas de contextualização que tem sido utilizadas para o ensino de equações nos livros didáticos, observando quais as mudanças que ocorreram passados 12 anos desde a implantação do Programa Nacional do Livro Didático (PNLD).

Pensamos neste tema devido à concepção elencada acima, e também em virtude de que no decorrer de minha graduação nas diversas discussões a respeito de como trazer o conteúdo de uma maneira mais interessante e atrativa para o aluno eram apontados fatores que evidenciavam a importância do ensino contextualizado, e utilizamo-nos do livro didático como objeto da pesquisa, pois o mesmo é uma ferramenta frequentemente utilizada como norteador da aula pelo professor.

A partir da definição deste tema nos dispomos a responder o seguinte problema de pesquisa quais as principais mudanças ocorridas no livro didático relativas à contextualização com a implantação do PNLD?

\section{Breve historia da álgebra}

A origem do nome álgebra segundo Eves (2004) vem do titulo do tratado de alKhowârizmi sobre o assunto "Hisâb al-jarb w'al-muqâ-balah", que em uma tradução literal quer dizer "a ciência da reunião e da oposição", uma parte deste texto que foi preservada tornou-se conhecida através de uma tradução latina e a partir da palavra al-jarb originou-se a palavra álgebra como ciência das equações.

Seu desenvolvimento pode ser caracterizado em três períodos históricos, no primeiro tem-se a álgebra retórica, que é caracterizada por não fazer uso de símbolos ou abreviações para representar o pensamento algébrico dessa forma era utilizada apenas a linguagem corrente para solucionar os problemas. Os Primeiros relatos de uma álgebra retorica, vem dos babilônicos, que por volta do ano de 2000 a.C. já tinha este método bem desenvolvido, de modo que conseguiam resolver equações quadráticas pelo método equivalente a substituição 
em uma formula geral e também pelo método de completar quadrados, além disso eram discutidas formas de resolução de equações cubicas e biquadradas.

No segundo período temos a álgebra sincopada, é nesta fase que acontece o inicio da utilização de abreviações para algumas quantidades e operações que se repetem na resolução de um problema. A álgebra sincopada tem seus primórdios através do matemático Diofanto que viveu em Alexandria, não se sabe ao certo o período em que ele viveu porem alguns historiadores o situem no século III. Em seu trabalho "Aritmética" o único que remanesceu de maneira completa até os dias atuais o matemático traz uma abordagem analítica sobre a teoria algébrica dos números, onde são discutidos 130 problemas que geram equações do primeiro e segundo graus e apenas uma equação cubica, porém Diofanto não fazia uso de métodos gerais e admitia apenas soluções racionais positivas, de modo que sua grande contribuição foi que ele pode ter sido o primeiro a fazer o uso de abreviações atribuindo-as para incógnitas, potências de incógnita até o expoente 6 , subtração, igualdade e inversos. Nesse período também temos os Hindus que da mesma forma serviram-se de uma álgebra sincopada, fazendo uso de abreviações para representar suas subtrações, produto, divisão e também para raiz quadrada assim como também existiam abreviações para representar incógnitas e constantes, através do uso de abreviações do nome de cores para incógnitas. Um aspecto importante é que segundo Cajori (1980, p.147) “Os indianos foram os primeiros a reconhecerem a existência de quantidades absolutamente negativas. [...] Também a concepção de direções opostas sobre uma reta, como interpretações do + e do -, não eram estranhas a eles.”. Porem, a álgebra retorica ainda continuou a ser muito utilizada no resto do mundo por muitos anos, ha exemplo disto a álgebra retorica permaneceu na Europa Ocidental até o século XV.

Por fim no terceiro período tem-se a álgebra simbólica na qual são utilizados símbolos, que por vezes nada tem haver com o objeto representado. A álgebra simbólica deve muito ao matemático francês François Viète que nasceu em 1540 e que embora não fosse matemático por profissão dedicava boa parte de seu tempo livre à matemática. Seu trabalho intitulado "In Artem Analyti com Isagoge" de 1591 introduz a pratica de representar incógnitas por vogais e constantes por consoantes, antes dele era comum que fossem utilizadas letras e símbolos diferentes para varias potencias de uma quantidade, entretanto Viète fazia uso da mesma letra com sua qualificação, ele também fazia uso dos sinais de $(+)$ e (-) embora não tivesse um símbolo para igualdade. O sinal de igualdade moderno por sua vez foi utilizado a principio por Robert Record em sua obra "The Whetstone of witte" que foi publicada em 1557 e 
segundo Record esse uso de dois segmentos de reta paralelos se dava pois "não pode haver duas coisas mais iguais".

Desta forma podemos ver de maneira breve como se deu o desenvolvimento da linguagem algébrica através da historia, mas o que vem a ser a álgebra?

\title{
Livro didático
}

O livro didático ocupa hoje um papel de grande importância dentro do ambiente escolar, pois, muitas vezes é o único material disponível ao professor como recurso de suporte para preparação de suas aulas, e também pode ser o único material impresso disponível para o uso dos alunos. Portanto a maneira que os conteúdos serão ensinados, frequentemente é norteada a partir deste recurso, dado sua maior acessibilidade tanto por parte dos alunos como dos professores.

Dada esta importância o governo federal aponta alguns fatores essenciais que o livro didático deve desempenhar, segundo Brasil (2014, p.53)

\begin{abstract}
É preciso que o livro didático contribua com o trabalho do professor no sentido de propiciar aos alunos oportunidades de desenvolver ativamente as habilidades envolvidas no processo de ensino e aprendizagem, e, além disso, buscar a formação dos alunos como cidadãos, de modo que possam estabelecer julgamentos, tomar decisões e atuar criticamente frente às questões que a sociedade, a ciência, a tecnologia, a cultura e a economia têm colocado ao presente e, certamente, colocarão ao futuro.
\end{abstract}

Desta forma uma vez que o livro didático ocupa um papel tão importante na sala de aula é necessário que conheçamos mais sobre ele. Primeiramente de acordo com o dicionário da língua portuguesa Houaiss(1999, p.626) livro é a "Publicação impressa que consiste em uma reunião de páginas ou cadernos de papel com textos impressos, costurados entre si." e também segundo Houaiss(1999, p.333) didático é "1.Escolar. 2. Relativo ao ensino. 3. Próprio para instruir" deste modo o livro didático pode ser compreendido como uma publicação impressa que é própria para instruir.

Também é importante compreendermos qual o papel que o livro didático vem desempenhando na historia brasileira não só no ambiente escolar, mas também social, cultural e político. Para isso faremos uma breve explanação sobre a historia do livro didático de matemática no Brasil que é relativamente recente uma vez que o primeiro livro didático escrito aqui segundo Valente (1999, apud Alves, 2005, p.29) data de 1744, com o titulo de "Exame de Artilheiros" e foi escrito por José Fernandes Pinto Alpoim com o intuito de ensinar a arte militar, nele eram discutidos temas da matemática necessários para compressão dos conteúdos militares, dentre os assuntos matemáticos abordados no livro temos, aritmética 
e geometria, e apesar deste livro ter sido escrito no Brasil devido à falta de impressas no Brasil colonial foi impresso em Lisboa. O primeiro livro didático de matemática a ser impresso no Brasil de acordo com Pfromm (1974, apud Alves, 2005, p.31) só ocorre em 1809 depois da vinda dos equipamentos de tipografia nos porões dos navios que trouxeram a família real em 1808, tendo como uma de suas primeiras publicações a tradução de autores europeus importantes como, por exemplo, a obra de Legendre "Os Elemento da Geometria e Tratado de Trigonometria" que segundo Biehl (2009) era utilizada na formação de alunos da academia militar do Rio de Janeiro.

Segundo Mantovani (2009, p.26) é apenas em 1929 que o governo federal começa a ter certa preocupação com os livros didáticos criando o Instituto Nacional do Livro (INL) que tinha o objetivo de legislar sobre o livro didático e contribuir para sua legitimação. Porém de acordo com Silva (2014, p.14)

\section{foi apenas em 1938, por meio do Decreto n. 1.006, de 30/12/1938, que se oficializou e regulamentou a primeira política de legislação e controle de produção e circulação do livro didático no Brasil, por meio dela se instituiu uma Comissão Nacional do Livro Didático (CNLD).}

Cujo objetivo era de examinar, julgar e indicar livros didáticos estrangeiros para a tradução visto que ainda não havia efetiva produção de livros didáticos nacionais e também sugerir abertura de concursos para produção de outras espécies de livros didáticos ainda não existentes no país. Ainda de acordo com Silva esta preocupação do governo em avaliar os livros didáticos se dava, pois através dos livros o governo conseguia transmitir os objetivos buscados pelo Estado para a população, mesmo assim Biehl $(2009$, p.2) destaca que já era possível que os professores fizessem a escolha do livro a ser utilizado a partir de uma lista pré-determinada por lei. De acordo com Silva(2014) durante o período da ditadura militar (1964 a 1984) houve severo controle sobre o sistema educacional e nos matérias didáticos utilizados e novamente os livros didáticos eram utilizados como ferramentas para a disseminar os ideais políticos defendidos pelo governo vigente, deixando em segundo plano o papel principal do livro que é o de auxiliar no processo de ensino.

De acordo com Silva $(2014$, p.15) "Com o fim do período militar no Brasil, por meio do Decreto $n^{\circ}$ 91.542, de 19/08/1985 foi criado um novo programa responsável pela compra e distribuição dos livros didáticos o Programa Nacional do Livro Didático (PNLD)" programa este que permanece até os dias de hoje, em ciclos de três anos com o objetivo que segundo o site do MEC é "de subsidiar o trabalho pedagógico dos professores por meio da distribuição de coleções de livros didáticos aos alunos da educação básica". Ainda de acordo com Silva 
apesar de sua criação em 1985 seu efetivo funcionamento só se dá a partir de 1996 com o inicio da avaliação pedagógica dos livros que iriam compor o PNLD 1997.

Visto que o Programa Nacional do Livro Didático (PNLD) esta em funcionamento até os dias atuais, e que o mesmo será um dos objetos de estudo desta pesquisa iremos aprofundar nossos estudos sobre ele. Atualmente em sua sexta edição para alunos dos anos finais do ensino fundamental, este programa fornece livros de Língua Portuguesa, Matemática, Ciências, História, Geografia e Língua Estrangeira Moderna (Inglês e Espanhol), que segundo Brasil (2014) são avaliados em três momentos: a triagem que se destina a examinar os aspectos físicos e atributos editoriais das coleções inscritas, a pré-análise que consiste no exame do atendimento da documentação necessária definida em edital, e a avaliação pedagógica que é realizada por instituições publicas de educação superior, de acordo com as orientações e diretrizes estabelecidas pelo Ministério da Educação. A avaliação pedagógica se dá a partir de critérios comuns tais como respeito à legislação, observância de princípios éticos, correção e atualização de conceitos, entre outros e também sobre critérios específicos, que caso sejam encontrados erros implicam na exclusão do livro no processo de seleção e consequentemente na exclusão de toda coleção. Estes critérios apontados por Brasil (2014, p.67) para o livro de matemática são:

1. apresentar erro ou indução a erro em conceitos, argumentação e procedimentos matemáticos, no livro do aluno, no Manual do Professor e, quando houver, no glossário;

2. deixar de incluir um dos campos da Matemática escolar, a saber, números e operações, álgebra, geometria, grandezas e medidas e tratamento da informação;

3. der atenção apenas ao trabalho mecânico com procedimentos, em detrimento da exploração dos conceitos matemáticos e de sua utilidade para resolver problemas;

4. apresentar os conceitos com erro de encadeamento lógico, tais como: recorrer a conceitos ainda não definidos para introduzir outro conceito, utilizar-se de definições circulares, confundir tese com hipótese em demonstrações matemáticas.

5. deixar de propiciar o desenvolvimento, pelo aluno, de competências cognitivas básicas, como: observação, compreensão, argumentação, organização, análise, síntese, comunicação de ideias matemáticas, memorização;

6. supervalorizar o trabalho individual;

7. apresentar publicidade de produtos ou empresas.

Dentre os critérios específicos são levantadas questões que são de extrema importância para o efetivo aprendizado do aluno tais como o critério 3 onde fica evidenciada a aspiração de que o ensino seja trabalhado de maneira que venha construir algo além da execução de algoritmos, isto é, que ele desenvolva seu raciocínio matemático. Não deixa de lado também itens indispensáveis como no ponto 2 onde é expressa a preocupação com a completude dos assuntos que fazem parte do currículo escolar ou nos pontos 1 e 4 onde existe o cuidado para com a inexistência de erros bem como situações que possam induzir a eles, e também no 
ponto 5 onde são apresentadas as habilidades básicas que devem ser trabalhas no livro didático.

\title{
Contextualização
}

Não é de hoje que o ensino de matemática passa por dificuldades, mesmo que em outras disciplinas existam impedimentos e entraves, é em matemática que boa parte dos alunos sente maior dificuldade, e como destaca Vasconcelos (2007, p.14) "apesar da importância atribuída ao ensino e à aprendizagem de Matemática, o que percebemos é que o seu ensino tem sido caracterizado por altos índices de reprovação, fomentando nos indivíduos a crença de que essa ciência é direcionada apenas a pessoas particularmente talentosas”. Um dos aspectos que dificultam a aprendizagem dos alunos e contribui para esse tipo de pensamento é que, muitas vezes os assuntos são apresentados sem uma justificativa anterior que possa legitimar seu estudo e também, que cada conteúdo é trabalhado de maneira separada e sem ligações com outros assuntos anteriormente estudados, o que é prejudicial para a formação do aluno como é destacado por Brasil (2014, p.52):

\begin{abstract}
A apresentação de conceitos e procedimentos sem motivação prévia, seguida de exemplos resolvidos como modelo para sua aplicação em exercícios repetitivos é danosa, pois não permite a construção, pelo aluno, de um conhecimento significativo e condena esse aluno a ser um simples repetidor de procedimentos memorizados.
\end{abstract}

Ainda a respeito disto Vasconcelos (2007, p.18) aponta também que

na maioria das salas de aula, os conteúdos são trabalhados de forma isolada, sem conexões com outros conceitos ou conhecimentos relativos a outras disciplinas. Além de serem mecânicas e repetitivas, as situações de aprendizagem, geralmente, não estão centradas na construção de significados e na elaboração de estratégias próprias para a resolução de problemas, mas em atividades que envolvem memorização.

Considerando tais entraves que dificultam o aprendizado de matemática um recurso pedagógico que se apresenta como uma possível solução para estes problemas é a contextualização matemática. Pois como é evidenciado por Luccas e Batista (2007, p. 9)

\footnotetext{
A contextualização dos objetos matemáticos pode estimular os alunos para que se sintam motivados a aprender, principalmente quando envolve um contexto diferente do puramente matemático [...] Outro aspecto possibilitado pela contextualização consiste em saciar determinados questionamentos presentes no âmbito escolar, tais como: Por que é importante aprender isto? Em que situações cotidianas eu vou utilizar o que estou aprendendo? O que tem a ver isto que estou estudando em Matemática com a minha vida?
}

Portanto acreditamos que o ensino contextualizado pode ter grande relevância, para a resolução dos entraves sentidos pelos alunos como já citado. Contudo, mesmo que esta se apresente como uma possível solução é necessário que se tenha certa cautela, por que na busca de contextualizar os assuntos a qualquer custo em muitos casos a definição deste termo 
não é compreendida em sua totalidade, fazendo com que sejam gerados novos problemas como é citado por Fernandes (2006, p.7)

Boa parte dos professores acredita que o ensino contextualizado é aquele em que o professor deve relacionar o conteúdo a ser trabalhado com algo da realidade cotidiana do aluno. Esta realidade cotidiana é quase sempre interpretada como sendo a vida extra-escolar dos educandos. Desta concepção resulta que, conteúdos que não são fáceis de contextualizar, nestes termos, não se faz necessário trabalhar

Santos, Oliveira e Oliveira (2013, p.5) também se alinham a esta compreensão e evidenciam que

Embora as situações do dia-a-dia tenham grande importância no sentido de favorecer a construção de significados para muitos conteúdos a serem estudados, faz-se necessário considerar a possibilidade de construção de significados a partir de questões internas da própria Matemática, caso contrário, muitos conteúdos seriam descartados por não fazerem parte da realidade dos alunos.

Desse modo é importante que se conheça o que de fato é contextualizar, para evitar seu uso incorreto. De acordo com Tufano (2002, p.40) contextualizar é o ato de colocar no contexto, ou seja, colocar alguém a par de alguma coisa, uma ação premeditada para situar um indivíduo em um lugar no tempo e no espaço desejado, ou ainda segundo ele pode ser entendido como uma argumentação.

Para Souza (2014, p.26) que traz a contextualização a partir de uma perspectiva da matemática contextualizar é

o trabalho com a Matemática presente em diferentes campos científicos, visando promover a atribuição de significados e a compreensão da mesma como resultado de um processo histórico, que inclui idas e vindas para o desenvolvimento de determinado conceito, além da compreensão dessa ciência como articulada tanto a outras áreas do conhecimento, quanto a outros campos da Matemática e às práticas sociais.

Assim, contextualizar no ensino de matemática é levar o discente a compreender os aspectos históricos, sociais e interdisciplinares que perpassam determinado conteúdo.

Isto posto iremos agora buscar compreender quais e como são as formas de contextualização apresentadas por alguns autores.

Em seu trabalho Silva e Santo apresentam e discutem as seguintes formas de contextualização: no cotidiano do aluno, na historia da matemática, a interdisciplinaridade e o contexto da matemática pela matemática.

Ao discutir sobra a contextualização no cotidiano do aluno Silva e Santos (2004, p.4) apontam que "Essa forma de contextualização do conhecimento matemático, é a mais difundida, sobretudo porque é a forma clássica defendida por alguns dos pesquisadores da educação matemática" apontando como um dos principais defensores dessa linha pensamento o grupo de estudo representado por Terezinha Nunes e difundido a partir do livro "na vida dez 
na escola zero". Acreditamos que este tipo de contextualização aparece como o mais difundido também devido a sua maior facilidade de abordagem, uma vez que é de consenso geral que matemática esta presente no cotidiano, quer por meio de formas geométricas encontradas em construções, quer por uma comparação de preços realizada entre produtos ou até mesmo ao fazermos a verificação de um troco. Contudo é reiterado pelo autor de que esta não seja a única forma de contextualização, pois ao fazermos isto estaríamos dando ênfase unicamente a matemática aplicada, o que é um equívoco dado que "O conhecimento é um só e é o contexto de direcionamento de interesses que faz ora ser matemática aplicada, ora ser pura"(SILVA; SANTO, 2004, p.6).

Ao tratar sobre a contextualização na história da matemática ou como é colocado pelos autores "o conhecimento contextualizado no tempo e no espaço". Silva e Santo (2004, p.7) apontam que

Se o conhecimento escolarizado é resultante da sistematização do conhecimento matemático formalizado pelos matemáticos que por sua vez, em grande parte, tiveram sua influência da matemática do cotidiano (sobretudo os conceitos mais básicos, como o conceito de número natural e as operações básicas), então é mister que esses conceitos possam ser apresentados aos alunos com uma recontextualização no tempo e no espaço.

Portanto através da contextualização no tempo e no espaço é possível que seja apresentada as motivações que levaram ao desenvolvimento de determinado conhecimento cientifico, contribuindo assim para desconstrução do pensamento de que a matemática é uma ciência que está pronta ou cristalizada, mostrando também as idas e vindas necessárias para a construção do saber como é apresentada na definição de contextualização de Souza. Desta forma como é evidenciado por Fossa (2001 apud SILVA, SANTOS 2004, p.7) podemos considerar que "a História da Matemática é uma das formas de se contextualizar o ensino da Matemática escolarizada como possibilidades de situar o conhecimento no tempo e no espaço bem como motivar os alunos para um despertar para a aprendizagem da matemática".

Logo em seguida é discutida a contextualização através da interdisciplinaridade onde Silva e Santos (2004, p.8) afirmam que “A contextualização do conhecimento matemático em conteúdos de outras disciplinas é uma das formas de se mostrar a contribuição da matemática na leitura dos diversos fenômenos naturais e sociais em que outras ciências se apresentam.". Ou ainda como é exposto por Fernandes (2006, p.9)

\footnotetext{
A contextualização do conhecimento matemático em conteúdos de outras disciplinas é uma outra forma de mostrar a contribuição da Matemática na leitura dos diversos fenômenos naturais e sociais em que outras ciências se apresentam. A interdisciplinaridade consiste nisso, em utilizar os conhecimentos de várias disciplinas para resolver um problema ou compreender um determinado fenômeno sob diferentes pontos de vista.
} 
Portanto acreditamos que esta maneira de contextualizar pode ressaltar o valor da matemática como ferramenta a ser utilizada para compreensão de fenômenos naturais, ou ainda uma vez empregado por outras ciências mostrar o seu uso no cotidiano dos alunos.

A contextualização da matemática pela matemática e dividida por Silva e Santo em dois modos o pró-ativo e o retroativo. O contexto pró-ativo deve ser utilizado quando o conteúdo abordado é muito abstrato para a compreensão dos alunos, neste caso para Silva e Santos (2004, p.10) o docente deve "situar o raciocínio do aluno a partir de um conceito que seja uma forma mais elementar daquele conhecimento considerado.”. Já no contexto retroativo a ideia seria partir de um conhecimento mais difícil para melhorar a compreensão de outros mais simples e esta forma de contextualizar segundo Silva e Santo (2004, p.13) pode ainda "resolver um dos problemas sérios do ponto de vista da formação do professor: a capacidade para justificar um conteúdo com vistas à motivação do aluno para o estudo e à aprendizagem significativa." Pois esta apresentaria quais as utilidades de conteúdos previamente estudados.

Além destas formas de contextualização acima destacadas Luccas e Batista(2007) apesar de não discutir a seu respeito afirmam que a contextualização pode ocorrer também através da metodologia de resolução de problemas, para tanto acreditamos que primeiro seja necessário a compreensão do que realmente constitui um problema que segundo Lester(1982 apud Dante 2011, p.12) é "uma situação que um individuo ou grupo quer ou precisa resolver e para a qual não dispõe de um caminho rápido e direto que o leve à solução", portanto quando se propõe a trabalhar contextualização através de problematizações é necessário que seja apresentado mais que um simples exercício de aplicação de formulas, primeiramente é necessário que seja gerado nos alunos o desejo de resolver tal problema e também que os discentes não disponham de uma solução mecânica e direta para o mesmo, sendo assim é possível que esta forma de contextualização se integre com as demais fortalecendo assim o uso de cada uma delas.

\section{Metodologia}

Para realizarmos a escolha da coleção a ser analisada, observamos os editais do PNLD dos anos de 2014, 2011, 2008, 2005, 2002, 1999 buscando verificar quais os autores que estavam presentes em mais edições. A partir desta analise pudemos constatar que os livros de Iracema Mori e Dulce Satiko Onaga bem como os livros de Luiz Márcio Imenes e Marcelo Lellis estavam presentes em todas as edições do PNLD citadas acima. Entretanto devido a 
maior facilidade de acesso que tivemos aos livros de Iracema e Dulce optamos por adotar esta coleção em nossa pesquisa.

Para isto estabelecemos quatro categorias de contextos que serão nossa base para a analise do livro didático, tais categorias encontra-se na tabela a seguir, e foram elaboradas tendo como base as categorias elencadas por Silva e Santo(2004) em seu trabalho.

Tabela 1: Categorias de Análise.

\begin{tabular}{|c|l|}
\hline A. Contextualização Histórica. & $\begin{array}{l}\text { Aquela em que são apresentadas motivações ou } \\
\text { justificativas históricas para o surgimento daquele } \\
\text { conteúdo. }\end{array}$ \\
\hline B. Contextualização Interdisciplinar. & $\begin{array}{l}\text { Aquela em que a matemática é utilizada como } \\
\text { ferramenta para auxiliar a compreensão de } \\
\text { fenômenos de outras ciências. }\end{array}$ \\
\hline C. Contextualização interna à Matemática. & $\begin{array}{l}\text { Aquele em que conteúdos matemáticos mais } \\
\text { básicos são apresentados como fundamento para } \\
\text { conteúdos mais complexos ou aquele os conteúdos } \\
\text { complexos são delimitados e aprofundados } \\
\text { chegando a seus conteúdos basilares. }\end{array}$ \\
\hline D. Contextualização em Praticas Sociais. & $\begin{array}{l}\text { Aquela que são trazidos elementos do cotidiano do } \\
\text { aluno como situações motivadoras ou de aplicação } \\
\text { daquele conteúdo. }\end{array}$ \\
\hline
\end{tabular}

A partir destas categorias realizamos a analise nos livros didáticos apenas nos capítulos destinados ao ensino de equações do primeiro grau com uma variável. Sendo observadas primeiramente a forma como o assunto é apresentado e em seguida os exercícios propostos pelo livro didático.

\section{Análise e discussão dos resultados}

\section{Livro I}

Estaremos considerando como o livro I a obra da $6^{\circ}$ serie do ensino fundamental "para aprender matemática" de Iracema Mori e Dulce Satiko Onaga que possui 248 paginas e está dividida em 13 capítulos, dos quais apenas um será nosso objeto de estudo, sendo este o capitulo 7 que tem por titulo "Equações do $1^{\circ}$ Grau com Uma Variável". Este livro foi publicado em 1998 e, portanto é anterior a implantação do PNLD nos anos finais do ensino fundamental, nos possibilitando assim observar a forma como era utilizada a contextualização matemática antes do PNLD. Apresentaremos a seguir alguns recortes deste livro que podem ser enquadrados em nossas categorias de contextualização previamente citadas em nossa metodologia. 


\section{Discussão dos conteúdos}

Contextualização Histórica: Em todo o capitulo destinado a equações do primeiro grau pudemos encontrar a utilização da contextualização histórica em apenas um caso como podemos observa na figura abaixo.

Figura 1: Contextualização Histórica I.

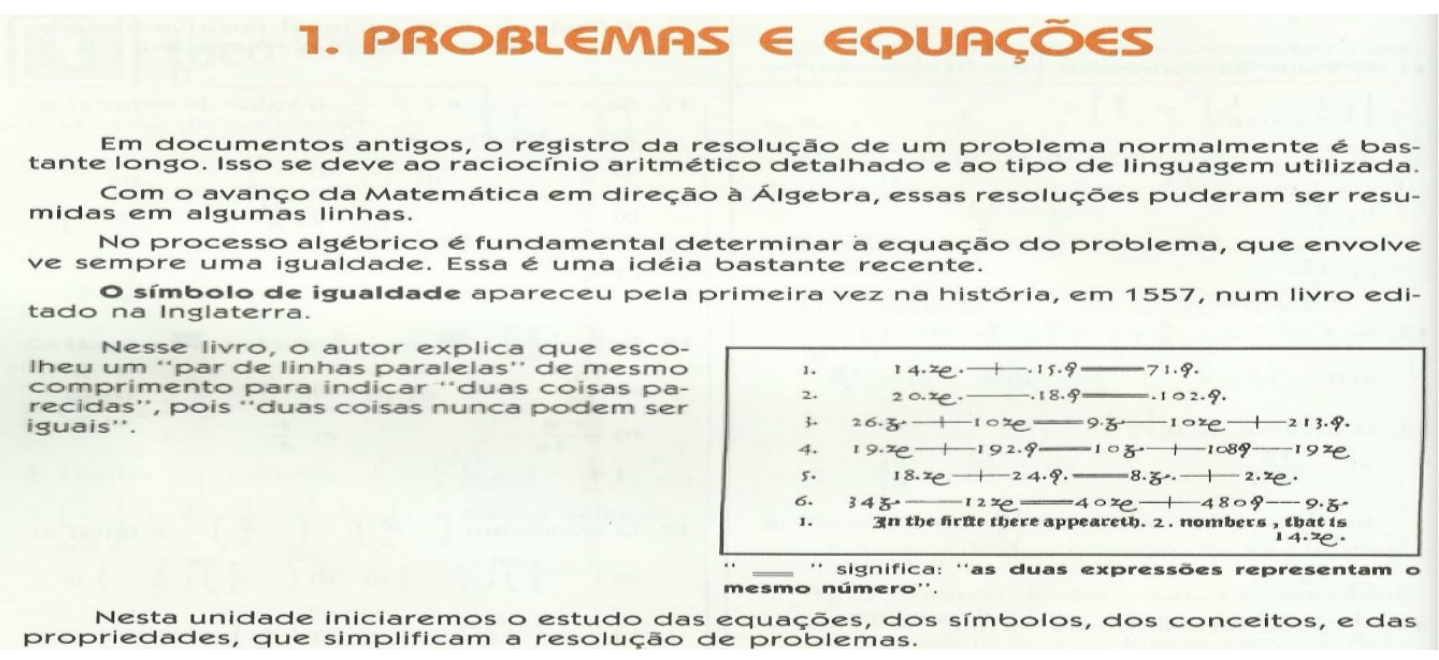

Fonte: Mori e Onaga, 1998, p.112.

Podemos notar que o Livro didático utiliza de forma sutil da contextualização histórica para motivar o estudo da álgebra, uma vez que ele apresenta a mesma surgindo a partir de uma dificuldade dos matemáticos, que era o tamanho das resoluções de um problema, no entanto ao fazer isto o livro comete um equivoco, pois ao utilizar a expressão "Com o avanço da matemática em direção a álgebra" ele passa a ideia de que antes das resoluções de problemas em poucas linhas (entendemos isto como a álgebra simbólica) o que havia não era álgebra, o que baseado em nosso primeiro capitulo esta incorreto, pois desconsidera a existência da álgebra retórica e sincopada. Ainda nesta figura, podemos notar que as autoras apresentam uma curiosidade histórica que é a criação do sinal de igualdade, porém seu uso fica restrito a simples apresentação deste fato.

Contextualização interna à Matemática: Nesta categoria em que buscamos encontrar ligações que possam ser feitas entre o estudo de equações e outros conteúdos matemáticos, pudemos encontrar o uso do contexto pró-ativo citado por Silva e Santo em pelo menos dois casos, pois como ilustrado nas figuras a seguir, as autoras se preocupam em partir de estruturas matemáticas mais simples, a saber, expressões algébricas e sentenças matemáticas, para construção da definição de equação, ou seja, o aluno é situado no conteúdo 
de equações a partir de conceitos de menor complexidade, como podemos ver na figura a seguir.

Figura 3: Contextualização interna à Matemática

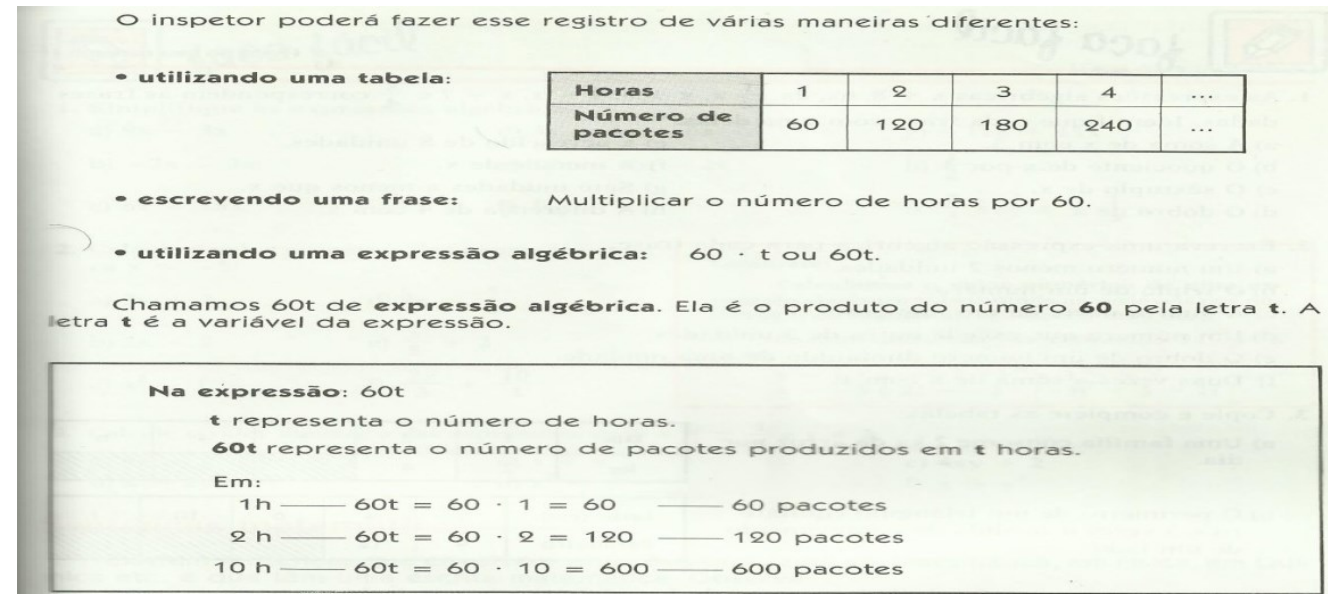

Fonte: Mori e Onaga, 1998, p.113.

Ao trabalhar expressões algébricas, um fator interessante é que as autoras introduzem este conceito através de uma questão, a qual os discentes não possuem ferramentas que os levem a uma solução rápida e direta da mesma, sendo assim desde que seja bem trabalhada pelo docente, a mesma pode vir a ser caracterizada como um problema de acordo com a metodologia da resolução de problemas. Além disto, ao apresentar a solução da questão, o livro não se limita a expor apenas uma forma de soluciona-lo, exibindo algumas soluções possíveis para só então trazer a tona a ideia de que todas as soluções sugeridas até então podem ser sintetizadas a partir do uso de expressões algébricas.

Contextualização em Praticas Sociais: Em nossa análise pudemos identificar neste capitulo do livro didático apenas uma contextualização desta forma, que se repetiu em dois casos, o que contradiz nossa hipótese inicial de que esta seria uma das formas de contextualização mais utilizadas. Apresentamos a seguir um dos casos que foram encontrados, 
Figura 2: Contextualização em praticas sociais

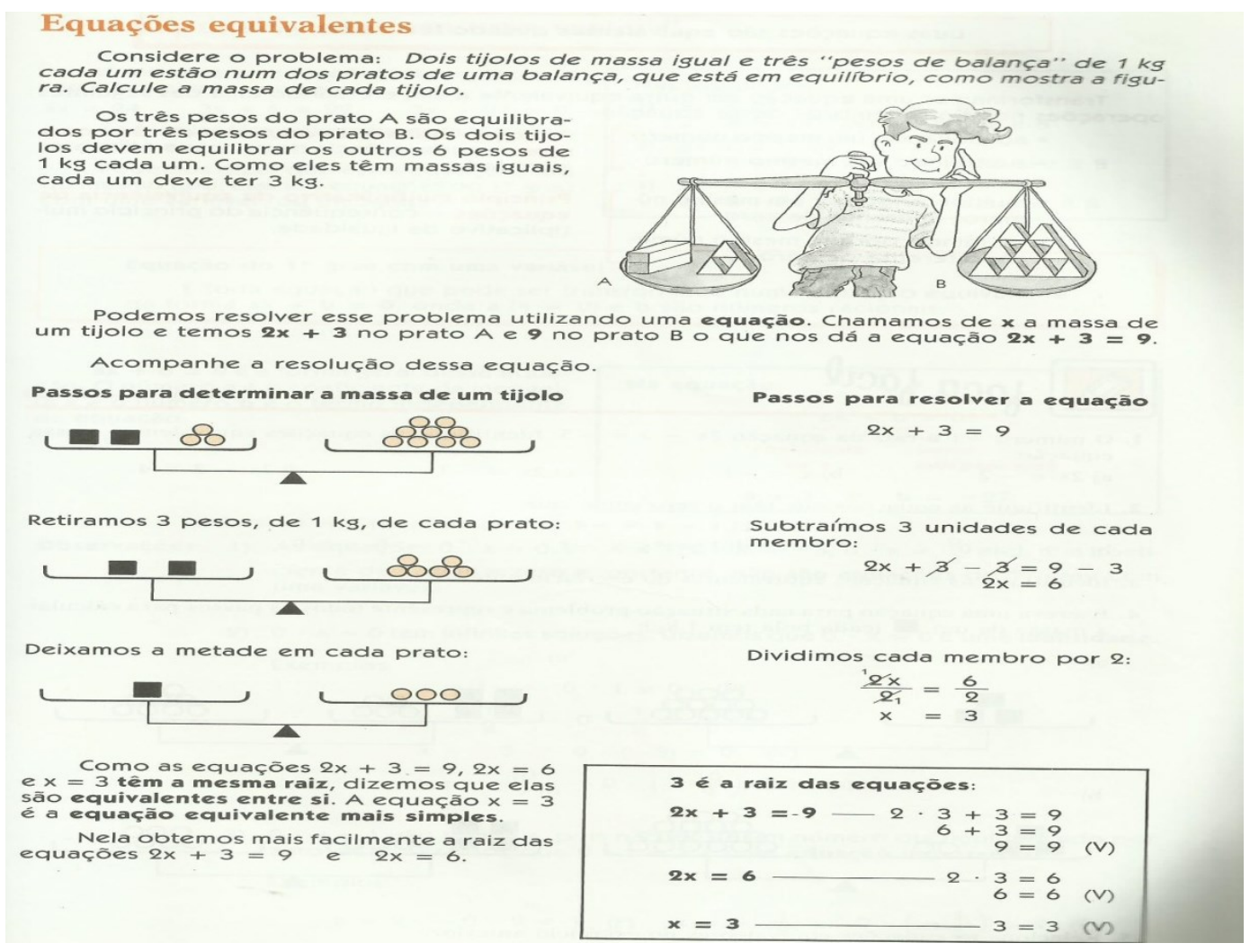

Fonte: Mori e Onaga, 1998, p.123.

Podemos observar que a pratica social utilizada como contexto neste caso é o uso da balança de dois pratos, e que a mesma ocorre para a introdução das propriedades dos princípios aditivo e multiplicativo de equivalência, esta contextualização é congruente ao seu proposito uma vez que possibilita ao aluno formular suas próprias ideias e atribuir significados a estas ferramentas matemáticas, vale salientar ainda, que esta pratica social era de presença mais marcante no cotiando dos alunos no ano de lançamento deste livro, hoje a mesma ainda se constitui como uma forma de contextualização no entanto seu principio necessita ser explicado pois este tipo de balança não é mais presente de forma tão marcante no cotidiano dos alunos.

Contextualização Interdisciplinar: Neste capitulo do livro didático analisado não encontramos nenhum uso da contextualização interdisciplinar na exposição dos conteúdos.

\section{Discussão das questões}

Identificamos 131 questões que se dividem da seguinte forma: 
Gráfico 1: Percentual das atividades livro I.

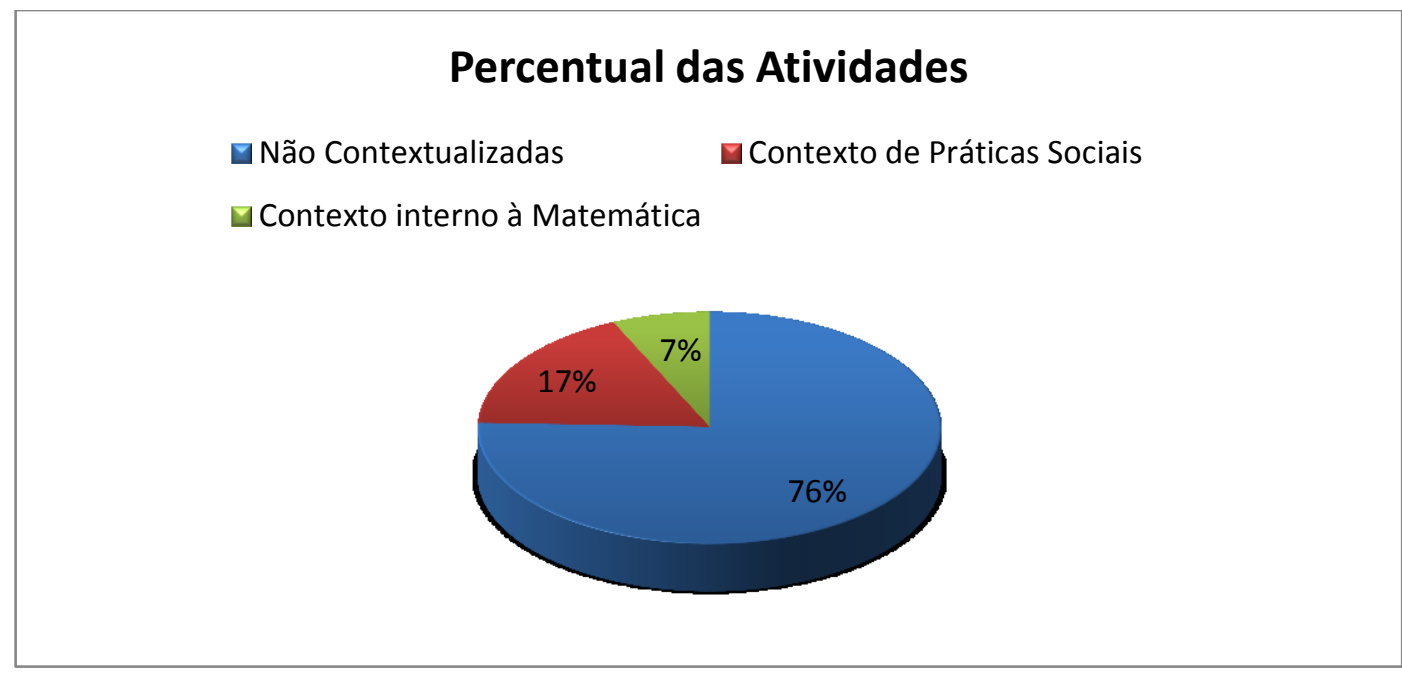

Podemos observar a partir do gráfico acima, que a grande maioria das questões são trazidas de maneira descontextualizada, limitando-se muitas vezes a comandos como simplifique, calcule, identifique, entre outros que se caracterizam por serem mecânicos e devido a sua grande quantidade se tornam repetitivos, pois além de estarem em maior numero estas questões em muitos casos se subdividem em varias "letras". O que a partir da implantação do PNLD passaria a ser bastante criticado, por não permitir ao aluno a construção de um conhecimento significativo como já citamos em nossa fundamentação.

\section{Livro II}

Estaremos considerando como o livro II a obra do $7^{\circ}$ ano do ensino fundamental "Matemática ideias e desafios" de Iracema Mori e Dulce Satiko Onaga que possui 304 paginas e está dividida em 10 unidades, das quais apenas uma será nosso objeto de estudo, sendo esta composta por três capítulos, a saber, $O$ uso de letras em matemática, Equações de $1^{\circ}$ grau com uma incógnita e Equações e resolução de problemas. Este livro foi publicado em 2012 e atende as exigências do PNLD 2011. O qual ao apresentar sua visão geral a respeito do livro entre outro fatos destaca que

A tônica da obra é a contextualização dos conteúdos na própria matemática escolar. Há, por outro lado, um número significativo de atividades que envolvem contextos sociais, ambientais, históricos ou de outras áreas do saber. Estes servem de base para a formulação de questões sobre conceitos e procedimentos matemáticos, mas se explora pouco a discussão de outros aspectos da situação abordada. (BRASIL, 2011, p.53)

Portanto através da descrição feita pelo PNLD esperamos encontrar maior numero de contextualizações e ainda que estas estejam divididas de forma mais harmônica que no Livro I. 


\section{Discussão dos conteúdos}

Contextualização Histórica: Ao longo da unidade destinado a equações podem ser encontradas ao menos quatro situações que se caracterizam como contextualização histórica, logo ao iniciar o capitulo podemos encontrar o seguinte uso desta:

Figura 3: Contextualização Histórica II.

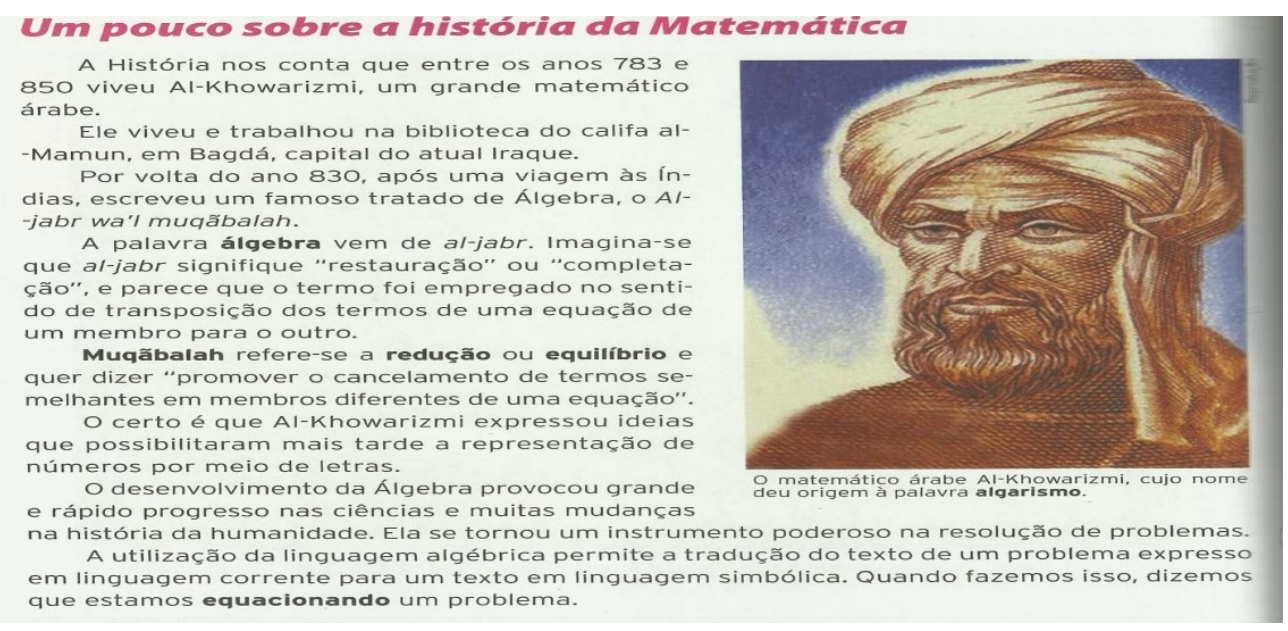

Fonte: Mori e Onaga, 2012, p.146.

Podemos observar que neste caso o uso da contextualização histórica possibilita aos discentes ter conhecimento sobre a origem do termo "álgebra", em seguida é feita uma alusão à importância deste instrumento na resolução de problemas, no entanto, os fatos históricos apresentados não possuem ligação direta que possa validar a importância deste instrumento, e portanto ainda que álgebra possua tal relevância não há fundamentação lógica que sustente esta afirmação, desse modo não existe um uso motivacional do fato histórico apresentado e a motivação feita não recebe fundamentos que lhe deem suporte.

Pudemos também nos deparar com o uso do mesmo fato histórico encontrado no livro I que recebeu uma nova caracterização como podemos observar a seguir:

Figura 4: Contextualização Histórica III.

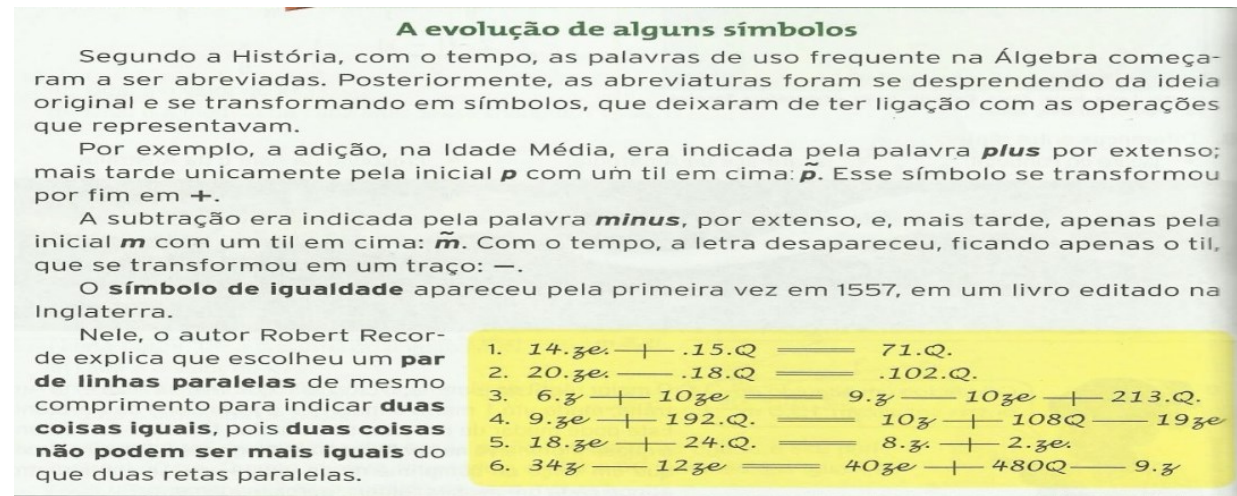

Fonte: Mori e Onaga, 2012, p.176. 
Com esta contextualização é possível despertar no aluno a ideia de que a matemática não é uma ciência estagnada, uma vez que a mesma ilustra o desenvolvimento símbolos matemáticos que atualmente são de uso recorrente em resoluções de problemas através da álgebra, descontruindo assim a concepção de que a matemática é imutável. Também com relação a este fato histórico foi corrigido a expressão que no livro I transmitia a ideia de que antes da utilização de símbolos o que havia não era álgebra.

De um modo geral o uso das contextualizações históricas neste capitulo se dá de uma forma sucinta e superficial, necessitando assim que haja a intervenção do docente para que as mesmas possam despertar nos alunos a motivação e curiosidade para se aprofundar no assunto e então se apropriar de uma visão critica a respeito do conteúdo.

Contextualização Interdisciplinar: Na apresentação dos conteúdos não encontramos nenhuma referência direta que considerássemos como um contexto interdisciplinar, no entanto, em um primeiro momento ao apresentar a unidade referente ao estudo de equações temos a imagem do físico teórico Albert Einstein como podemos ver na figura abaixo:

Figura 5: Contextualização interdisciplinar I.

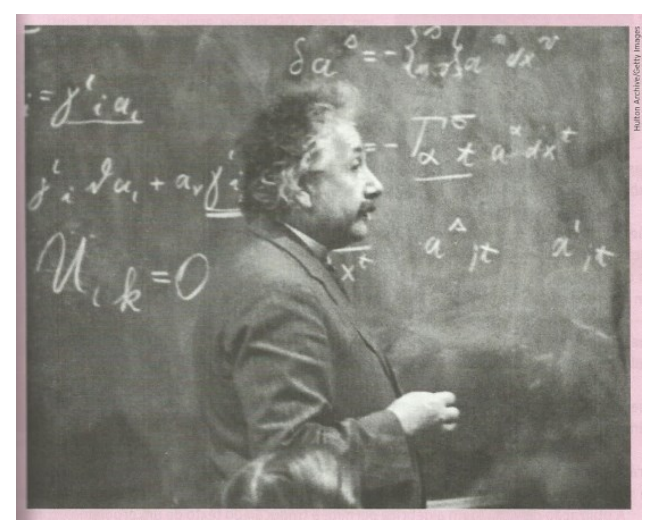

Fonte: Mori e Onaga, 2012, p.145.

Esta imagem permite ao professor tecer um breve comentário a respeito do uso do conteúdo de equações por outras ciências, a exemplo disto a própria física, trazendo assim novamente a contextualização como um motivador para o estudo deste conteúdo fazendo assim que possivelmente o aluno possa legitimar o estudo deste conteúdo.

Contextualização interna à Matemática: Neste tipo de contextualização pudemos encontrar dois casos de seu uso o primeiro acontece de forma bem semelhante ao que encontramos no livro I com expressões algébricas e por este motivo não o discutiremos mais aprofundada. O segundo caso que encontramos pode ser observado na figura a seguir: 
Figura 6: Contextualização interna à Matemática III.

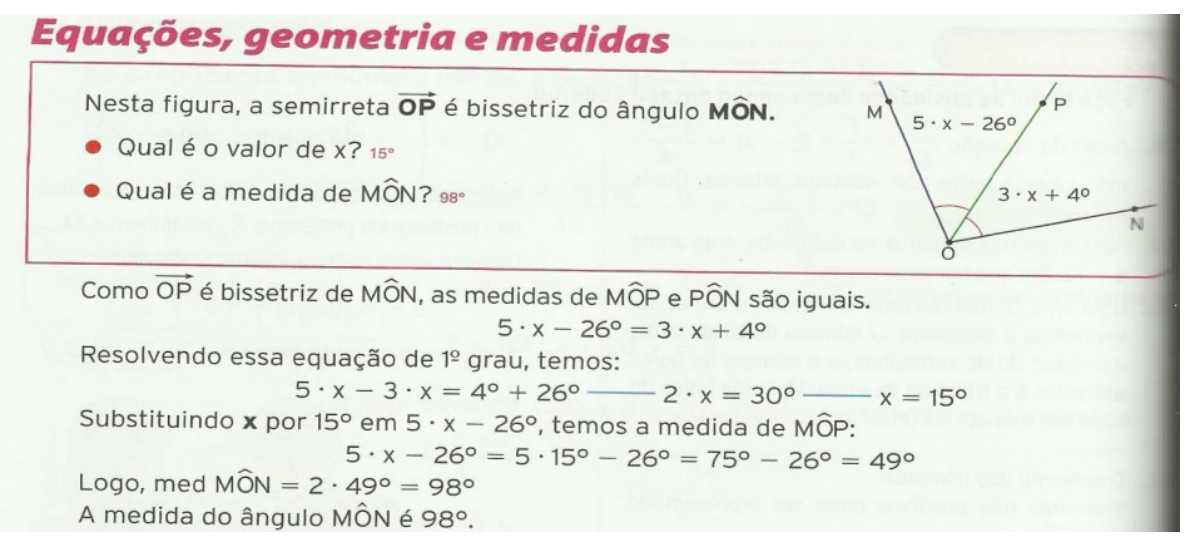

Fonte: Mori e Onaga, 2012, p.174.

Podemos notar que a contextualização acontece fazendo a ligação do conteúdo de geometria com equações, porém ainda que este se caracterize como uma interligação entre dois conteúdos matemáticos é explorado de maneira muito breve sendo o conteúdo desta figura todo o assunto trabalhado, desta forma entendemos que a mesma foi inserida apenas para mostrar a existência de tal ligação sem uma preocupação com sua real relevância para o aprendizado.

Contextualização em Praticas Sociais: Esta forma de contextualização se apresentou como sendo uma das mais utilizadas neste capitulo do livro didático estando presente em ao menos oito casos, dos quais podemos destacar os seguintes:

Figura 7: Contextualização em praticas sociais II.

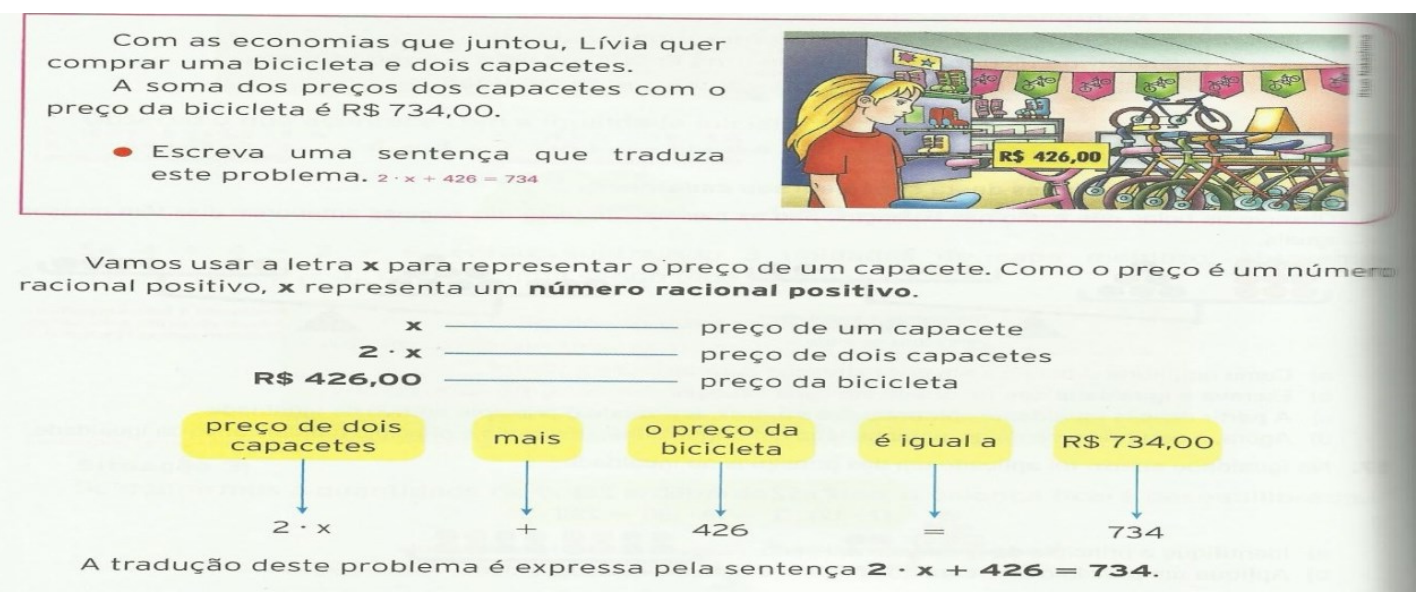

Fonte: Mori e Onaga, 2012, p.158.

Este problema é apresentado como sendo o primeiro contato que os alunos terão com equações neste capitulo do livro didático, podemos observar que o contexto social criado apesar de ser fictício poderia acontecer no cotidiano do aluno, outro fator importante a ser 
considerado nesta questão é que a figura apresentada não é meramente ilustrativa mas contem dados que serão importantes na resolução do problema. Na resolução do problema o livro didático inicia trabalhando aquilo que seria a primeira concepção de álgebra abordada por Usiskin que é da álgebra como uma generalizadora modelos, isto é, o problema é traduzido de uma linguagem materna (português) para a linguagem matemática, e partir disto a equação assume sua forma canônica. E só então é apresentado o conceito formal de equação, logo em seguida é utilizado o contexto de uma balança de dois pratos que já havia sido por ele apresentado para contextualizar as propriedades do princípio aditivo e multiplicativo da igualdade, é importante destacar que antes do primeiro uso deste contexto de balanças foi trazida uma breve explicação do funcionamento deste tipo de balança o que é importante uma vez que esta não esta presente no cotidiano dos alunos como outrora.

Um outro exemplo de contextualização em praticas sociais que podemos destacar é feito ao ser apresentado o conceito de simplificação de expressões algébricas como podemos verificar nas figuras abaixo:

Figura 15: Contextualização em praticas sociais IV.
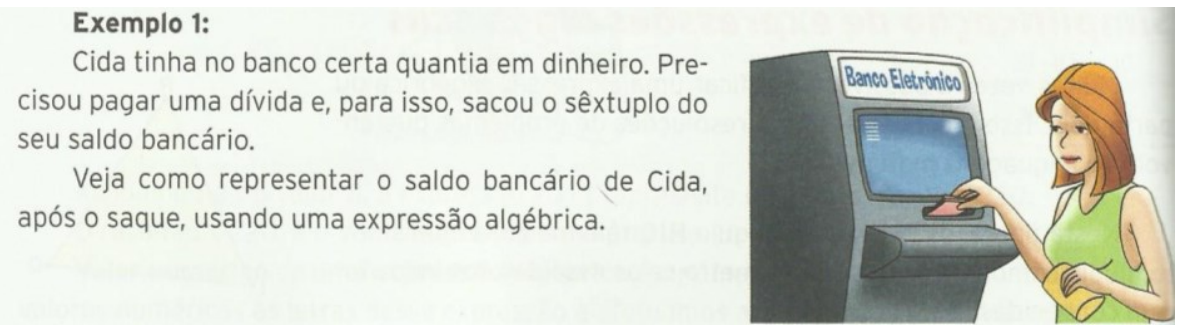

Fonte: Mori e Onaga, 2012, p.150.

Podemos notar neste uso da contextualização, que a situação proposta apesar de partir de uma pratica do cotidiano adquire características totalmente desligadas da realidade diferentemente do exemplo anterior, outro ponto negativo desta contextualização é que a figura que foi apresentada em nada interfere na resolução da questão sendo assim é completamente dispensável. Quando é feita a exposição da resolução é adotada uma postura também semelhante ao que descrevemos no exemplo anterior onde primeiramente é feita uma tradução da linguagem materna para a linguagem matemática e então são utilizadas técnicas para a simplificação da expressão.

\section{Discussão das questões}

Neste capitulo encontramos 86 questões que se dividem da seguinte forma: 
Gráfico 2: Percentual das atividades livro II.

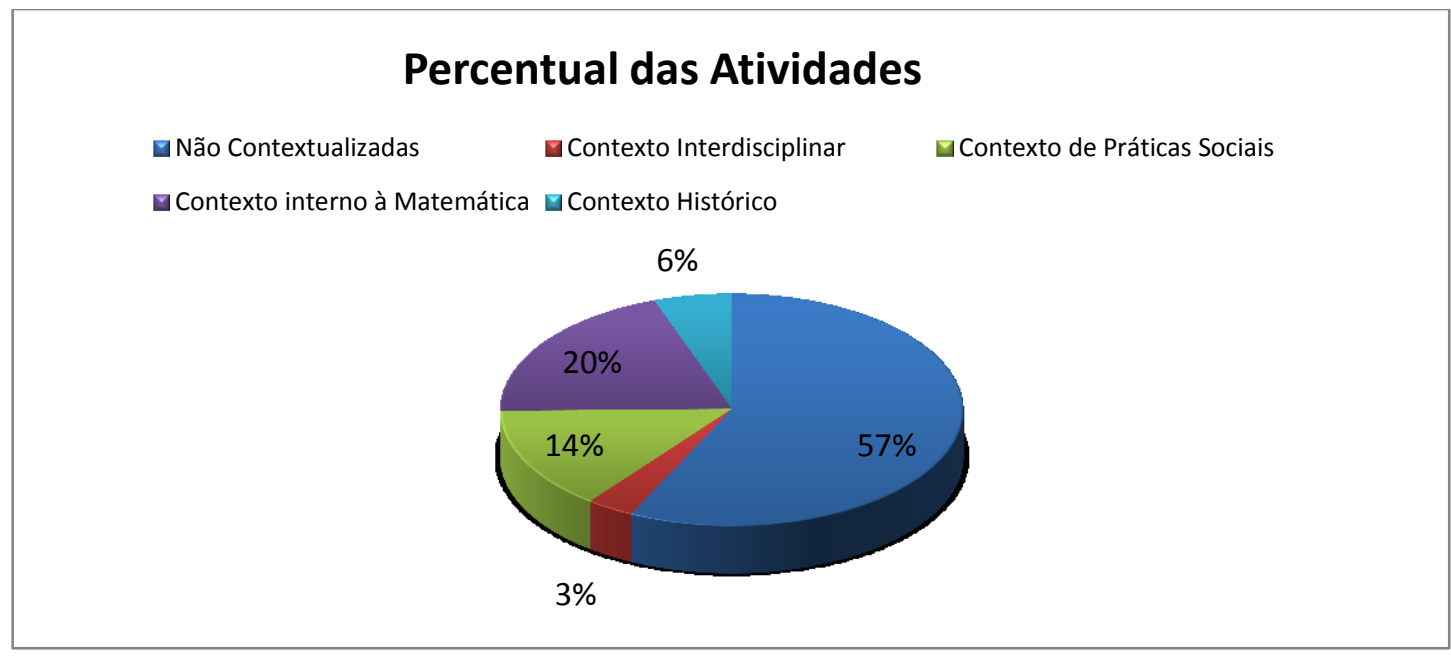

Podemos perceber a partir do gráfico acima que a maioria das questões é trazida de forma descontextualizada trazendo comandos para que o aluno execute o calculo. No entanto podemos encontrar também em numero significativo questões que apresentam alguma forma de contextualização.

\section{Análise comparativa entre livros I e II}

O gráfico a seguir ilustra as mudanças que ocorreram na distribuição das questões encontradas nos livros didáticos:

Gráfico 3: Comparação entre Livro I e II.

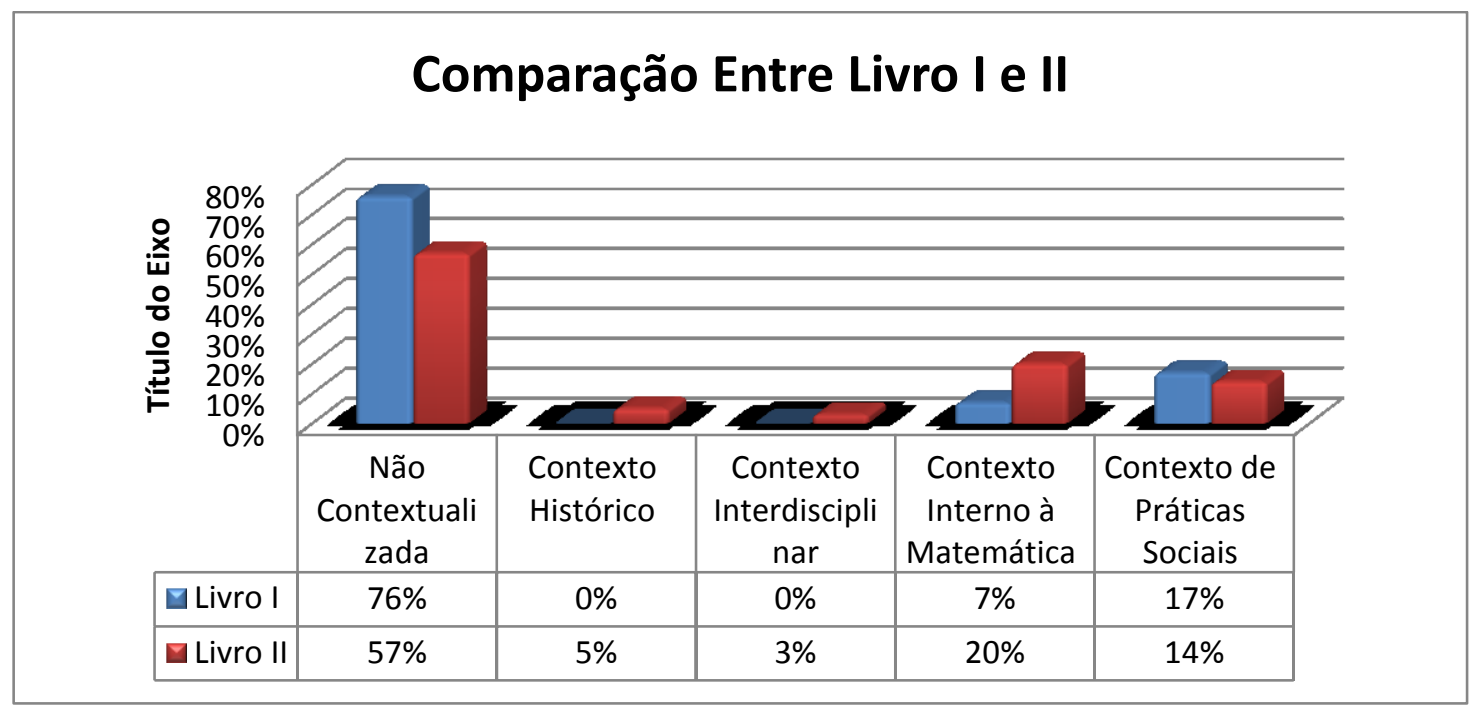

A partir do gráfico 3 podemos notar que nas duas obras analisadas o enfoque das questões é na forma não contextualizada, entretanto é possível notarmos uma diminuição significativa no número deste tipo de contextualização entre o livro I e II, o que possivelmente 
demonstra uma maior preocupação com a forma que as questões são trazidas a partir da implantação do PNLD. Outro fator importante que podemos destacar a partir da analise do gráfico é que enquanto no Livro I havia grande diferença entre a quantidade de questões contextualizadas a partir das praticas sociais e em contextos internos a matemática, no Livro II esta diferença caiu consideravelmente estando assim melhor harmonizadas entre si não priorizando apenas uma maneira de contextualização.

Apesar desta harmonização tida no livro II entre os contextos Social e Interno à Matemática, o contexto interdisciplinar aparece ainda pouco utilizado, estando presente em apenas três questões no Livro II o que pode representar um avanço em relação ao livro I que não possui nem ao menos uma questão desta forma, mas ainda está muito abaixo de uma quantidade que possa ter significação efetiva para a formação do aluno.

Já o contexto histórico que também não aparece em nenhuma questão do capítulo analisado no livro I, pode ser observado em algumas questões logo no inicio da unidade no livro II, com a existência desta forma de contextualização os alunos podem começar a desconstruir ideias erradas a respeito da matemática, ideias tais como o pensamento de que a matemática é uma ciência que esta pronta e acabada não admitindo mudanças e que ela sempre esteve pronta desta forma, pois ainda sendo apenas 5 perguntas geram no aluno um posicionamento no momento histórico e também algumas das motivações que levaram ao desenvolvimento deste conteúdo.

Quanto a forma como os assuntos são apresentados nos Livros didáticos, podemos notar que no livro II as contextualizações são mais presentes e estão melhor distribuídas no decorrer dos capítulos analisados, diferentemente do que é encontrado no livro I onde contextualizações acontecem de forma bem mais pontual e discreta. Outro fator que pode ser relevante é uso figuras que o avanço tecnológico possibilitou ao livro II trazer em maior quantidade e qualidade, fazendo com que além de um contexto "falado" possam haver imagens que ilustrem o que esta sendo dito.

Desta forma acreditamos que a partir da implantação do PNLD houveram mudanças significativas na forma como são apresentados os conteúdos nos Livros didáticos uma vez que forma observadas mudanças na distribuição e na forma como são feitas as contextualizações. Portanto acreditamos que em edições futuras deste livro didático possam ser observadas ainda mais avanços que possivelmente foram propiciados pela exigências contidas nos editais do PNLD.

\section{Considerações finais}


A partir das analises feitas no decorrer desta pesquisa, foi possível constatarmos que a as principais formas de contextualização utilizadas pelo livro didático são feitas a partir de práticas sociais bem como de contextos internos à matemática, contextos tais como o histórico e o interdisciplinar são pouco trabalhados no decorrer da obra analisada. Foi-nos possível também perceber que houve grande avanço na forma como as contextualizações são trazidas, a exemplo disto podemos observar o que ocorreu na contextualização de práticas sociais onde no livro antes do PNLD as contextualizações quase sempre tratam de situações muito artificiais enquanto no livro pós PNLD existem questões que são retiradas situações que realmente ocorreram, possibilitando assim mais proximidade ao discente.

Podemos observar também que muitas das contextualizações trazidas pelo livro didático apresentam situações que necessitam da intervenção do professor para que seu sentindo possa ser compreendido de forma integral, o que nos motiva a pensar em uma nova pesquisa que busque compreender como ocorre a relação entre professor, livro didático e a contextualização.

Outro ponto que foi possível ser observado é que nos capítulos dos livros didáticos analisados tanto no livro I como no Livro II são priorizadas questões não contextualizadas, o que pode ser reflexo de que os capítulos analisados estão construindo uma introdução ao assunto e por este motivo fazerem com que o aluno execute o mesmo calculo diversas vezes para sua memorização, no entanto deve haver certa cautela para que não ocorra a pratica de uma memorização de algoritmos que não possuem significado algum para o discente pois tal pratica é prejudicial e é combatida pelo próprio PNLD.

\section{Referências}

ALVES,A.M.M; Livro Didático De Matemática: Uma Abordagem Histórica (1943 1995). 188f. Dissertação (Mestrado em Educação)- Universidade Federal de Pelotas, Pelotas. 2005. http://www.educadores.diaadia.pr.gov.br/arquivos/File/2010/artigos teses/MATEMATICA/di ssertacao_antonio_mauricio_medeiros_alves.pdf Acesso em: 09/09/2015.

ARAUJO, A. J. de. O ensino de Álgebra no Brasil e na França: um estudo sobre o ensino de equações do $1^{\circ}$ grau à luz da teoria antropológica do didático. Tese de doutorado, UFPE, 2009. ce $=1 \&$ isAllowed $=y>$ Acesso: $20 / 10 / 2015$.

BARBOSA, E. J. T. Equação do Primeiro grau em livros didáticos sob a ótica da teoria antropológica do didático. Dissertação de mestrado, UEPB. 2011. Disponível em: < http://tede.bc.uepb.edu.br/jspui/bitstream/tede/1833/1/PDF\%20-

\%20Edelweis\%20Jose\%20Tavares\%20Barbosa.pdf> Acesso em: 20/10/2015. 
BIEHL, J.V; BAYER, A; A Escolha Do Livro Didático De Matemática. Disponível em: < http://www.projetos.unijui.edu.br/matematica/cd egem/fscommand/CC/CC 43.pdf $>$ Acesso em:15/05/2015.

BRASIL. Edital De Convocação 06/2011 - Cgpli 2014

BRASIL. Guia de livros didáticos: PNLD 2011: Matemática. - Brasília : Ministério da Educação, Secretaria de Educação Básica, 2010. 96 p. Disponível em: $<$ http://www.fnde.gov.br/arquivos/category/125-guias?download=6041:pnld-2011matematica> Acesso em: 20/11/2015.

CAJORI, F.(1980) Uma História da Matemática. Tradução: Lázaro Coutinho. Rio de Janeiro: Editora Ciência Moderna, 2007

COXFORD, A.F; SHULTE, A.P; As Idéias da Álgebra. São Paulo: Atual, 2004. 285p. in USISKIN, Z. As concepções sobre álgebra da escola média e utilizações das variáveis.

DANTE, L.R; Formulação e Resolução de Problemas de matemática - Teoria e Prática. Editora Atica. 2011.

EVES,H; Introdução à História Matemática. Tradução: Hygino H. Domingues. CampinasSP: Editora da Unicamp, 2004.

FERNANDES, S.S; A contextualização no ensino de matemática - um estudo com alunos e professores do ensino fundamental da rede particular de ensino do distrito federal. 2006 Disponivel

em: https://www.ucb.br/sites/100/103/TCC/22006/SusanadaSilvaFernandes.pdf Acesso em: 03/07/14.

HOUAISS, A; Dicionário Melhoramentos da Língua Portuguesa. 20.ed. São Paulo, 1999, Melhoramentos, 1126.

LINS, R.C; GIMENEZ, J; Perspectivas em Aritmética e Álgebra Para o Século XXI. $4^{\circ}$ edição. Campinas, SP: Papirus, 2001.176p.

LUCCAS, S; BATISTA, I.L; A Importância da Contextualização e da Descontextualização no Ensino de Matemática: uma Análise Epistemológica. Disponível em: $\quad$ http://www2.rc.unesp.br/eventos/matematica/ebrapem2008/upload/205-1-AMicrosoft $\% 20$ Word $\% 20-\% 20$ gt2 luccas ta.pdf Acesso em:03/07/14.

MANTOVANI, K.P; O Programa Nacional Do Livro Didático - PNLD Impactos Na Qualidade do Ensino Público. 126f. Dissertação Mestrado - Universidade de São Paulo. São Paulo 2009. Disponível em : < http://www.teses.usp.br/teses/disponiveis/8/8136/tde24112009-152212/publico/KATIA_PAULILO_MANTOVANI.pdf $>$ Acesso em: 09/09/2015

MORI, I.; ONAGA, D.S.; Matemática ideias e desafios. 17ª edição. Saraiva, 2012. 304p.

MORI, I.; ONAGA, D.S.; Para Aprender Matemática. $9^{\circ}$ edição. Saraiva, 1998. 248p. 
SANTOS, A.O.; OLIVEIRA, C. R.; OLIVEIRA, G.S.; A Contextualização no Processo de Aprendizagem da Matemática: Desafios e Possibilidades. Disponível em: http://vedipe.blessdesign.com.br/pdf/gt05/co\%20grafica/Anderson\%20Oramisio\%20Santos.p df. Acesso em: 05/11/15

SANTOS, J. A; FRANÇA, K.V; SANTOS L.S.B; Dificuldades na Aprendizagem de Matemática. $\quad$ São 2007.2 Paulo. 20 Disponível http://www.educadores.diaadia.pr.gov.br/arquivos/File/2010/artigos teses/MATEMATICA/ Monografia_Santos.pdf Acesso em:03/07/14.

SILVA, D.G; O Livro Didático No Processo De Ensino E Aprendizagem Da Matemática: Considerações De Professores De Escolas Públicas De Ji-Paraná. Ji-Paraná. 2014. Disponível em: http://www.dmejp.unir.br/menus_arquivos/17872014_daiane gomes.pdf Acessoem:25/08/15

SILVA, F. H. S; SANTO, A.O.E S; A contextualização: Uma questão de contexto. In VII ENCONTRO NACIONAL DE EDUCAÇÃO MATEMATICA. 2004, Recife. Disponível em: http://www.sbem.com.br/files/viii/pdf/07/CC08065128220.pdf Acesso em:02/12/2015

SOUZA, N.F; Contextualização no ensino da álgebra: análise de livros didáticos do $\mathbf{7}^{\mathbf{0}}$ ano. 2014. 107f. Dissertação (Pós Graduação em Educação Matemática) - Universidade Federal de Mato Grosso do Sul, Campo Grande - MS. 2014. Disponível em: http://files.ddmat.webnode.com/200000027-

$\mathrm{d} 5 \mathrm{~d} 26 \mathrm{~d} 6 \mathrm{cbd} /$ Disserta $\% \mathrm{C} 3 \% \mathrm{~A} 7 \% \mathrm{C3} \% \mathrm{~A} 3 \mathrm{o} \% 20 \mathrm{FInal} \% 20$ Naiara\%20Fonseca.pdf $\quad$ Acesso em:02/12/2015

TUFANO, W; IVANI, F; Dicionário em construção. São Paulo. $2^{\circ}$ Edição. Editora Cortez. 2002. 275p. Disponível em: http://www.institutoveritas.net/livrosdigitalizados.php?baixar=46 Acesso em: 03/07/14.

VASCONCELOS, M. B. F; A Contextualização e o Ensino da Matemática: Um Estudo de Caso. 18/12/2007. 113f. Dissertação (Mestrado em Educação Popular, Comunicação e Cultura) - Universidade Federal da Paraíba (UFPB), João Pessoa. 2007. Disponível em: http://www.ce.ufpb.br/ppge/index.php?option=com content\&task=view\&id=170\&Itemid=52 Acesso em 26/07/14. 